\title{
Remote spatial memory and the hippocampus: Effect of early and extensive training in the radial maze
}

\author{
Juan M.J. Ramos ${ }^{1}$ \\ Departamento de Psicología Experimental y Fisiología del Comportamiento, Facultad de Psicología, Campus de Cartuja, \\ Universidad de Granada, Granada 18071, Spain
}

\begin{abstract}
In a previous study we showed a temporally graded retrograde amnesia after hippocampal lesions when rats learned a spatial reference memory task in which two types of signals simultaneously indicated the goal arm (shape of the experimental room and extramaze landmarks). To investigate the effect that the navigational demands of the task have on remote memory expression, the same task was used in the present study as in our previous report, but on this occasion the shape of the surroundings was not predictive, which resulted in a highly demanding spatial task. Additionally, animals received extensive training in an early phase to ensure that the task was well learned. Results indicated a profound retrograde amnesia when dorsal hippocampal lesions were made 1 or $70 \mathrm{~d}$ after the end of the training (experiments 1 and 2). Using a long period of retraining, however, lesioned animals in the 70-d groups showed progressively more spared memory than the lesioned rats of the 1-d group. Experiments 3 and 4 showed that rats did not learn the above spatial task through an S-R association. Specifically, when animals acquired the task using a single cue (intra- or extramaze), hippocampal lesions did not produce retrograde amnesia. These findings support the possibility that in a highly demanding spatial task, hippocampal lesions produce a performance/navigational impairment that could interfere with the expression of spared remote spatial memory. The long period of retraining, however, seems to partially compensate for this deficit, but only when a long learning-surgery interval is employed.
\end{abstract}

The surprising observation that patient HM had profound amnesia for recent events, but still had access to remote memory, has prompted a number of studies about the nature and significance of retrograde amnesia (Milner et al. 1968, 1998; Squire 2009; see also Corkin 2002; Steinvorth et al. 2005; Salat et al. 2006). Over the last $15 \mathrm{yr}$, clinical observations in amnesic patients, for whom detailed neuropathological and neuropsychological information is available, have confirmed these initial data, showing graded retrograde amnesia following damage limited to the hippocampus or following large medial temporal lobe lesions (Squire et al. 2004a; Moscovitch et al. 2006). In these studies, profound amnesia for recent material (episodic and semantic) has been observed; however, while some laboratories have found remote semantic memories to be spared and remote episodic memories to be affected (Cipolotti et al. 2001; Gilboa et al. 2006; Noulhiane et al. 2007), others have reported that both remote semantic and episodic are spared (Manns et al. 2003; Bayley et al. 2006; Bright et al. 2006; Kirwan et al. 2008).

The identifiable gradient associated with retrograde amnesia has been a key factor in proposing theories about the specific role played by the hippocampus and its related cortices in memory (Frankland et al. 2007; Nadel et al. 2007). Thus, with the aim of looking further into the phenomenon of temporally graded retrograde amnesia, animal models of human memory impairment have recently been developed (Zola-Morgan and Squire 1990; for review, see Squire et al. 2004b; Frankland and Bontempi 2005). In rodents, graded retrograde amnesia has been easily reproduced using different nonspatial paradigms, for example, contextual fear (Kim and Fanselow 1992; Anagnostaras et al. 1999; Frankland et al. 2004; Wiltgen et al. 2006; Wang et al. 2009; but see Lehmann et al. 2007; Sutherland et al. 2008), social transmission

\footnotetext{
'Corresponding author.
}

E-mail jmjramos@ugr.es; fax 34-958-246239.

Article is online at http://www.learnmem.org/cgi/doi/10.1101//m.1480309. of food preference (Winocur 1990; Clark et at. 2002; see also Ross and Eichenbaum 2006), and trace eyeblink conditioning (Kim et al. 1995; Takehara et al. 2003). In all of these studies, recently acquired memories are typically more impaired than remote memories after hippocampal damage.

An intriguing aspect of the graded retrograde amnesia phenomenon, however, is that it appears elusive and inconsistent, and difficult to reproduce, when spatial tasks are used. Specifically, when using the water maze task, in general, the retrograde amnesia observed is flat, with both recent and remote memories being profoundly impaired (Bolhuis et al. 1994; Mumby et al. 1999; Sutherland et al. 2001; Clark et al. 2005a,b; Martin et al. 2005; Broadbent et al. 2006; Teixeira et al. 2006), with only a minor number of studies showing graded retrograde amnesia (Shimizu et al. 2000; Remondes and Schuman 2004). Somewhat more consistent results are found when the animals are trained in a spatial task in a radial-arm maze or when they must solve an allocentric problem in an open field. In this case, more than half of the studies published to date, have shown a temporally graded retrograde amnesia following hippocampal lesions or inactivation (Ramos 1998; Kubie et al. 1999; Maviel et al. 2004; see also Cho et al. 1993; Cho and Kesner 1996; Winocur et al. 2005a; Tse et al. 2007), while the others show a flat retrograde amnesia (LaurentDemir and Jaffard 1997; Winocur et al. 2005b; Haijima and Ichitani 2008). The absence of a hippocampal gradient in some of the aforementioned studies, however, does not mean that brain circuits involved in water- or radial-maze memories are not reorganized over time during systems-level consolidation, as other studies have shown in nonspatial paradigms (Takehara et al. 2003; Ross and Eichenbaum 2006). For example, in the Morris water maze test, the anterior cingulate cortex and the intralaminar thalamic nuclei are necessary for the expression of remote, but not of recent, memory (Teixeira et al. 2006; Lopez et al. 2009). Similarly, in place discrimination experiments using a radial maze, lesions to the anterior cingulate cortex and to the retrosplenial 
cortex disrupt the expression of remote, but not of recent, memory (Maviel et al. 2004; Haijima and Ichitani 2008).

In an attempt to explain this differential pattern of results obtained using nonspatial vs. spatial tasks, some authors have suggested that the hippocampus is always necessary to express spatial memory. If this is the case, hippocampal lesions may cause a deficit in performance rather than a memory impairment, so although remote spatial memory may be spared, the performance deficit impedes its expression (see Clark et al. 2007 for an exposition in greater depth). Specifically, it has been hypothesized that the hippocampus is necessary to update the spatial position of the animal, moment by moment, in order for a specific spatial memory to be expressed during the retention test (Knowlton and Fanselow 1998). Based on the foregoing, some authors have suggested that the navigational demands of the Morris water maze test are greater than those of the radial maze, which may explain why a larger proportion of studies have found a graded retrograde amnesia when employing the latter (Clark et al. 2007; Frankland et al. 2007).

In a previous study in the radial maze, we showed that dorsal hippocampus lesions produced a temporally graded retrograde amnesia (Ramos 1998). In this case, two types of signals were present simultaneously during the training and the retention phases, consistently indicating the location of the goal arm. Specifically, the extramaze constellation of stimuli and the shape of the experimental room (irregular shape, $7 \mathrm{~m}^{2} \mathrm{~L}$-shaped experimental room; see Ramos 1998, Fig. 1; Ramos 2000b, Fig. 3). The fact that two simultaneous series of cues indicated the position of the goal made our spatial reference memory task a very easy allocentric task, with only minimal navigational demands. In the present study, however, we have employed the same spatial task, but training and retention phases were performed in a regular experimental room (a totally square, $5 \times 5 \mathrm{~m}$ room) in which the shape of the experimental room was apparently not informative. Thus, a central goal of the present series of experiments was to investigate whether under these conditions, in which our task becomes a highly demanding spatial memory test, the graded retrograde amnesia previously found after hippocampal damage was maintained using our habitual training protocol in the radialarm maze. In order to compensate for, to some degree, a possible deficit in spatial memory expression on remote points, the training started early after weaning and continued until the animals had reached the age of $84 \mathrm{~d}$. A previous study using the water maze found a flat retrograde amnesia despite having trained the rats for the $69 \mathrm{~d}$ following weaning (five consecutive days each week) (Clark et al. 2005a). However, this possibility has not yet been tested in a task such as the radial maze, with fewer navigational demands than the water maze. To investigate this, we applied early and extensive training in the first two experiments of this series. The hippocampal lesions were made 1 or $70 \mathrm{~d}$ after acquisition. The retention phase took place on three consecutive days of retraining, and in this way, with such a long retention period, any possible spared remote spatial memory would have more opportunity to become visible, despite the possible performance deficit caused by the hippocampal lesion.

\section{Results}

\section{Experiment 1: Neurotoxic lesions of the hippocampus $1 \mathrm{~d}$ after learning}

It is generally established that dorsal hippocampal damage produces retrograde amnesia in rats for recent spatial information. The aim of this experiment was to investigate this idea, using our typical spatial reference memory task, when an extensive and early period of training is employed. A four-arm plus-shaped maze was used in such a way that three arms were for starting and the fourth was the goal arm. The training phase started postnatal day 28 and continued for five consecutive days each week for a total of $8 \mathrm{wk}$, with eight daily trials being performed. After a 1-2 d period following the last training session, rats received bilateral $N$-methyl-D-aspartate (NMDA) $(n=9)$ or sham lesions $(n=9)$ in the dorsal hippocampus. Twelve days after surgery, we examined spatial performance using a long period of retraining, with 16 daily trials being performed on three consecutive days. The rationale was that the rate of relearning should be greater the more presurgical spatial memory was spared. However, given that the rate of relearning could be contaminated by learning effects, performances of the lesioned and control groups were compared to that of additional groups of rats with hippocampal or sham lesions, but with no prior training. Thus, better performance during the retraining phase in the control-relearning group, as compared to the control-learning group, would reflect memory for the original preoperative allocentric information. An important objective of this experiment was to investigate whether this holds true for rats with hippocampal damage.

\section{Histology}

In order to quantify the extension of the lesion in each experimental rat, regions of cell loss and gliosis, identified microscopically, were plotted on drawings of coronal sections from the atlas of Paxinos and Watson (1998). For each hippocampus-lesioned rat, the reconstruction of the lesion was made based on nine coronal sections (anteroposterior levels from the interaural point: $+6.8,+6.2,+5.7,5.2,+4.7,+4.4,+3.8,+3.4$, and +2.9$)$. Each coronal section was digitized and the lesioned area was measured in square millimeters by a computer program (Autocard, version 2004). The volume of damage was expressed as a percentage of normal volume obtained from three normal nonlesioned rats.

A one-way ANOVA revealed that the extent of the hippocampal damage was similar in both lesioned groups (mean retraining group $=81.3 \pm 12.1$ vs. training without prior experience group $=78.9 \pm 13.2 ; F<1$ ). In most animals, the lesion began in the anterior pole of the hippocampus, at the most caudal level of the paraventricular nucleus (Fig. 1). At this level, the lateral twothirds appeared lesioned in all the animals, but the most medial portion was intact in most of the subjects. At more posterior levels, specifically at the level of the ventromedial nucleus of the hypothalamus and the mamillary nuclei, the lesion had the same configuration, with extensive zones showing necrosis or missing tissue in the hippocampal CA1, CA2, and CA3 fields. At these levels, in most cases the dentate gyrus was affected, but its most medial region appeared intact to varying degrees. In general, lesions ended between $3.2 \mathrm{~mm}$ and $2.8 \mathrm{~mm}$ posterior to the interaural point according to the atlas of Paxinos and Watson (1998), at the beginning of the Sylvius aqueduct. At this level the hippocampal CA1 field and the dentate gyrus were partially affected in $80 \%$ of the animals. In the remainder of the subjects, no lesion was observed.

\section{Behavioral results}

\section{Preoperative learning}

Figure 2A shows the performance of the hippocampal and control groups throughout the days of the preoperative training. A twoway ANOVA (group $\times$ day) indicated the absence of a significant effect between groups $\left(F_{(1,16)}=2.20, P=0.15\right)$, a significant effect of day $\left(F_{(39,624)}=117.37, P<0.0001\right)$, but no significant interaction between factors $(F<1)$.

\section{Postoperative retention}

Figure $3 \mathrm{~A}$ depicts the performance of the hippocampal and control groups during the three days of retraining. A two-way ANOVA 
EXPERIMENT 1
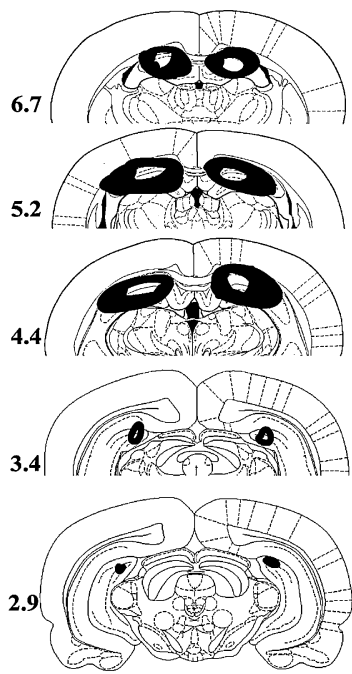

EXPERIMENT 3
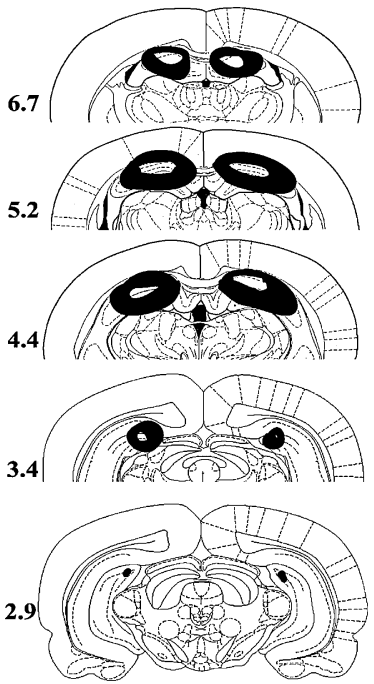
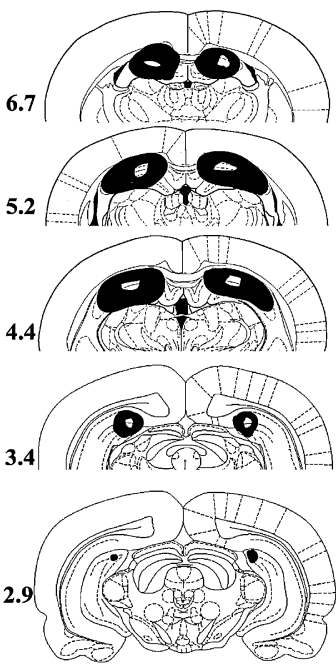

EXPERIMENT 4
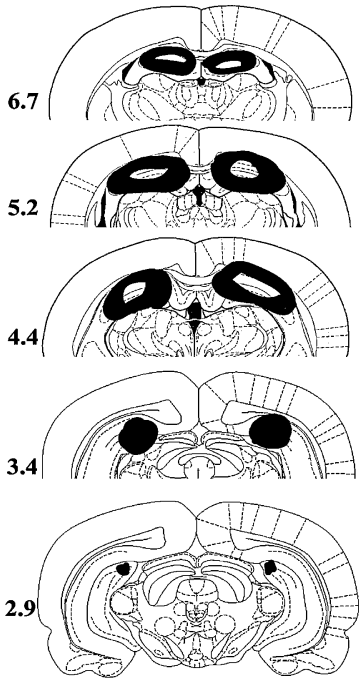

EXPERIMENT 2

Figure 1. Coronal sections showing the largest (gray) and smallest (central white area) hippocampal lesions. Anteroposterior coordinates are shown in relation to the interaural zero point.

(lesion $\times$ day) revealed a significant effect of lesion $\left(F_{(1,16)}=\right.$ $128.58, P<0.0001)$ and of day $\left(F_{(2,32)}=7.14, P<0.002\right)$, but not of interaction $(F<1)$.

In order to study whether relearning occurred during the three consecutive days of postoperative testing, two one-way ANOVAs of repeated measures were performed for the experimental and control groups. For the lesioned group, one-way ANOVA indicated no significant differences during the $3 \mathrm{~d}$ of testing $\left(F_{(2,16)}=\right.$ 1.85, $P=0.18$ ); however, significant differences were observed for the control group $\left(F_{(2,16)}=9.58, P<0.001\right)$. In an attempt to analyze in more depth the performance of the lesioned group, three $t$-tests showed no significant differences between the performance of the hippocampal group on each day of retraining and the performance expected by chance (first day of retraining, $t_{(8)}=$ $0.14, P=0.89$; second day, $t_{(8)}=1.43, P=0.18$; third day, $t_{(8)}=1.97$, $P=0.09)$. Finally, to find out whether there were differences between the additional groups without previous experience and the groups with previous training, two additional ANOVAs were performed. First, Figure 3B compares the performance of the lesioned group that had previous training with the performance of the lesioned group without presurgical training. A two-way ANOVA showed no significant effects $\left(F\right.$ group $<1 ; F_{(2,30)}$ day $=$ $2.49, P=0.09$; $F$ interaction $<1$; Fig. 3B). In contrast, a second twoway ANOVA between the two control groups (previous training vs. no previous experience), revealed a significant effect of group $\left(F_{(1,15)}=304.16, P<0.0001\right)$ and day $\left(F_{(2,30)}=12.90, P<0.0001\right)$, but not of interaction $\left(F_{(2,30)}=1.70, P=0.19\right.$; Fig. $\left.3 C\right)$.

\section{Experiment 2: Neurotoxic lesions of the hippocampus $70 \mathrm{~d}$ after learning}

Confirming previous studies, experiment 1 showed a profound retrograde amnesia for recent spatial information following hippocampal damage. The aim of experiment 2, however, was to investigate remote spatial memory under the same conditions of acquisition as in experiment 1 . Therefore, the only difference between the previous experiment and this one is that here hippocampal lesions were carried out $70 \mathrm{~d}$ after the last training session and that $12 \mathrm{~d}$ after the surgery we examined spatial performance of the remote information learned presurgically. As in experiment 1 , here we used a long period of retraining on three consecutive days, with a total of 48 trials. The rationale was that this long period of retraining might compensate to some extent for a possible deficit in performance that concealed spared memory.

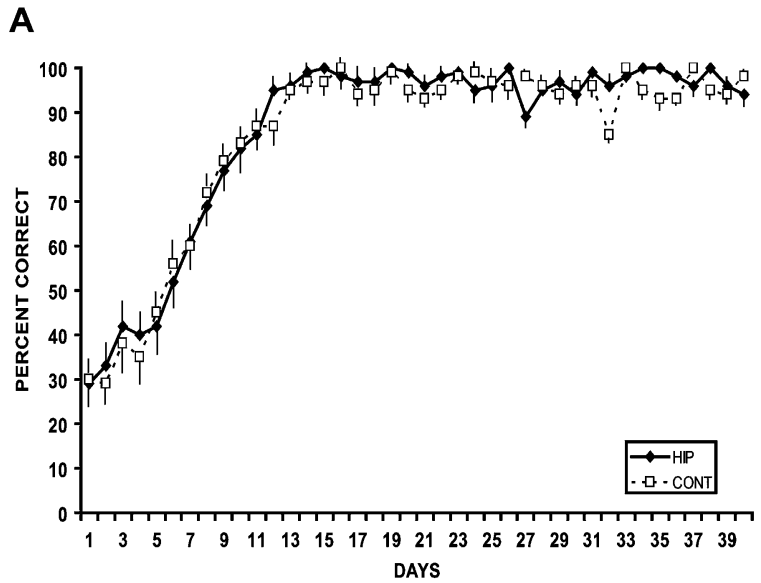

B

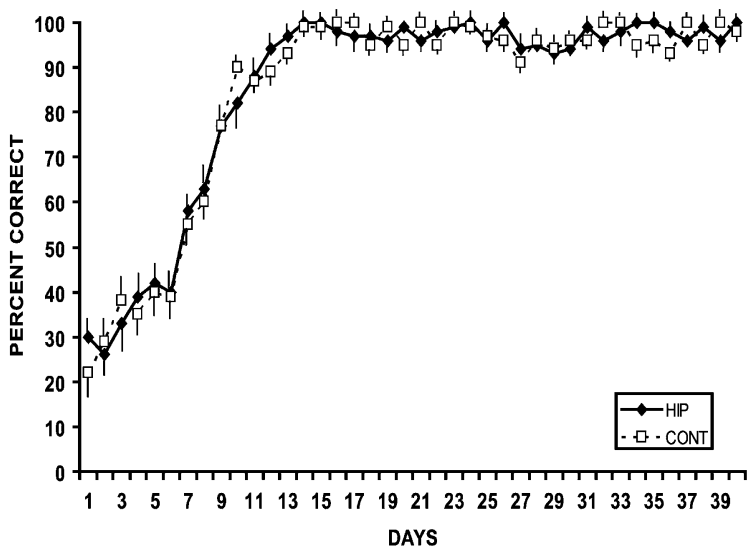

Figure 2. Mean ( \pm SEM) percentage of correct responses observed in hippocampus-lesioned and control groups during the $40 \mathrm{~d}$ of presurgical training of experiments $1(A)$ and $2(B)$. 


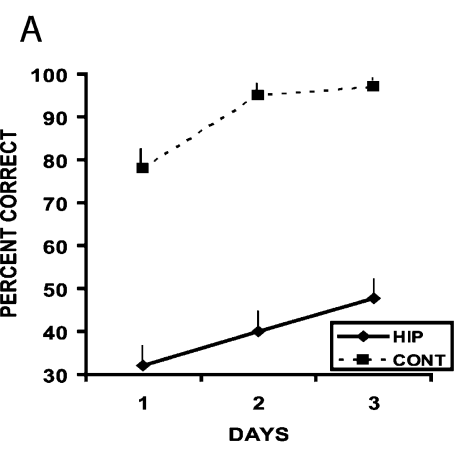

B

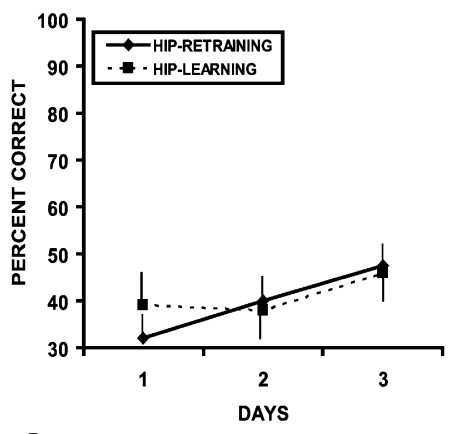

C

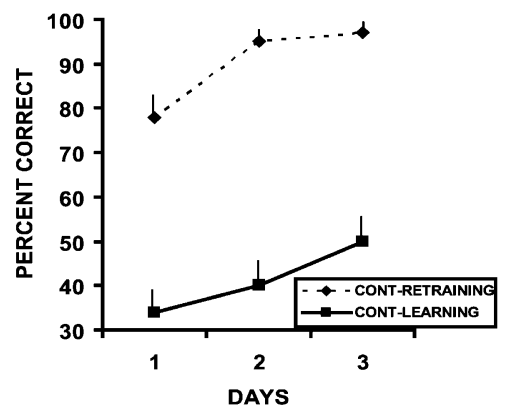

$\mathrm{D}$

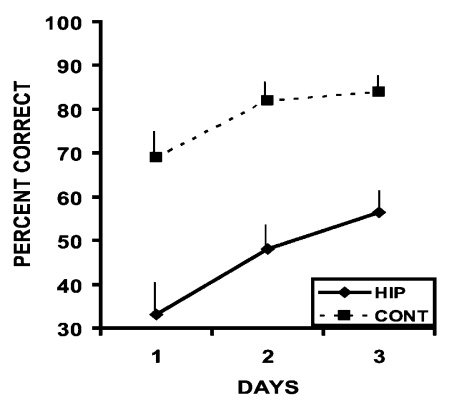

E

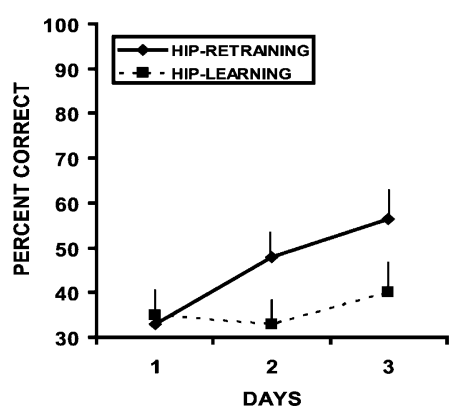

$\mathrm{F}$

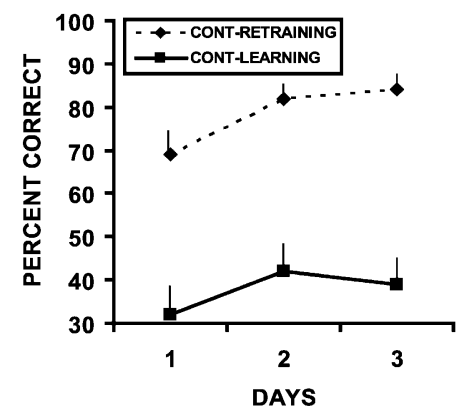

Figure 3. (A) Mean ( \pm SEM) percentage of correct responses observed in hippocampus-lesioned and control groups during the $3 \mathrm{~d}$ of retraining of experiment 1 . (B) Mean ( \pm SEM) percentage of correct responses observed in the hippocampus-lesioned group with previous training and in the hippocampus-lesioned group without experience during the $3 \mathrm{~d}$ of retraining of experiment 1 . (C) Mean ( \pm SEM) percentage of correct responses observed in the control group with previous training and in the control group without experience during the $3 \mathrm{~d}$ of retraining of experiment 1. (D) Mean ( \pm SEM) percentage of correct responses observed in hippocampus-lesioned and control groups during the $3 \mathrm{~d}$ of retraining of experiment 2. ( $E$ ) Mean ( \pm SEM) percentage of correct responses observed in the hippocampuslesioned group with previous training and in the hippocampus-lesioned group without experience during the $3 \mathrm{~d}$ of retraining of experiment 2. $(F)$ Mean ( \pm SEM) percentage of correct responses observed in the control group with previous training and in the control group without experience during the $3 \mathrm{~d}$ of retraining of experiment 2 .

\section{Histology}

A schematic reconstruction of the hippocampal lesions appears in Figure 1 . The extent of the hippocampal damage was very similar to that observed in experiment 1. One-way ANOVA indicated similar hippocampal damage for the lesioned animals of both experiments $(F<1)$.

\section{Behavioral results}

Preoperative learning

Figure 2B depicts the performance of the hippocampal and control groups throughout the $40 \mathrm{~d}$ of preoperative training. A two-way ANOVA (group $\times$ day) showed only a significant effect of day
$\left(F_{(39,624)}=116.26, P<0.0001\right)$, but not of group $(F<1)$ or of interaction $(F<1)$.

\section{Postoperative retention}

Figure 3D depicts the performance of the lesioned and sham groups during the retraining period. A two-way ANOVA (lesion $\times$ day) indicated a significant effect of lesion $\left(F_{(1,16)}=31.86, P<0.0001\right)$ and of day $\left(F_{(2,32)}=8.84, P<0.0008\right)$, but not of interaction $(F<1)$. Like in experiment 1 , in the present experiment the extent of relearning was analyzed in each of the groups. On this occasion, however, one-way ANOVA of repeated measures performed for the hippocampal group revealed a significant effect during the $3 \mathrm{~d}$ of retraining $\left(F_{(2,16)}=5.92, P<0.01\right)$, and a marginally significant effect was detected for the control group during the same period $\left(F_{(2,16)}=3.20, P=0.06\right)$. With regard to the lesioned group, on this occasion, $t$-tests indicated that the performance of this group was significantly higher than chance during the second $\left(t_{(8)}=2.36, P<0.04\right)$ and the third $\left(t_{(8)}=\right.$ $6.89, P<0.001)$ day of retraining.

To determine whether the improvement observed in the hippocampal group during the $3 \mathrm{~d}$ of retraining could be explained exclusively by a learning effect or whether, on the contrary, the preoperative memory retained by the rats contributed to this improvement, the performance of the lesioned group with previous training was compared to that of the lesioned group without previous training. The two groups were of the same age. As illustrated in Figure 3E, the group with preoperative training performed the task better starting on the second day of retraining. A two-way ANOVA revealed a marginally significant effect of group $\left(F_{(1,15)}=4.27, P=0.05\right)$, a significant effect of day $\left(F_{(2,30)}=5.41\right.$, $P<0.009)$, and no significant interaction $\left(F_{(2,30)}=2.47, P=0.10\right)$. Importantly, a comparison between panels $\mathrm{B}$ and $\mathrm{E}$ in Figure 3 shows the superiority of remote vs. recent memory, when a possible impairment in navigation/performance induced by the hippocampal lesions is controlled by the incorporation of groups without presurgical experience. Last of all, upon comparing the two control groups, with previous training vs. without previous training, a clear effect of group $\left(F_{(1,15)}=53.9, P<0.0001\right)$ and day $\left(F_{(2,30)}=4.72, P<0.01\right)$ was found, but not for interaction $(F<1$; Fig. 3F).

With the aim of analyzing the forgetting curves of the control and lesioned groups, we used data from experiments 1 and 2 . The analysis focused on the third day of retraining. For this day, a twoway ANOVA (group $\times$ learning-surgery interval) indicated a significant effect of group (lesion vs. control) $\left(F_{(1,32)}=80.72, P<\right.$ $0.0001)$ and of interaction $\left(F_{(1,32)}=4.40, P<0.04\right)$, but not of learning-surgery interval ( $F<1$; Fig. $4 \mathrm{~A})$. As illustrated in Figure $4 \mathrm{~A}$, an important piece of data that emerged after this analysis is 
A

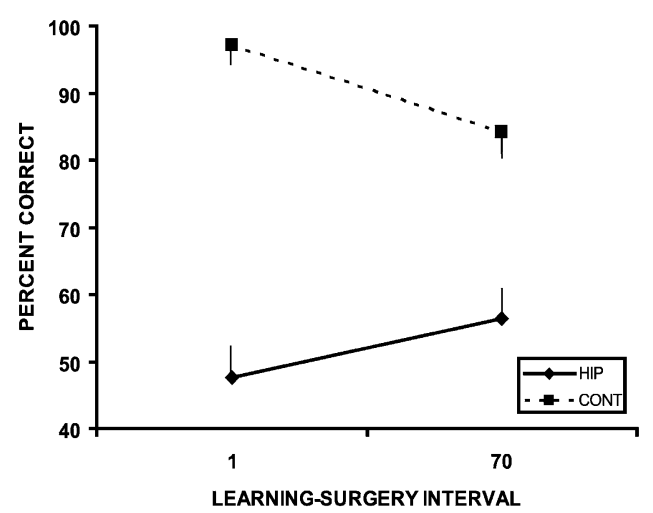

B

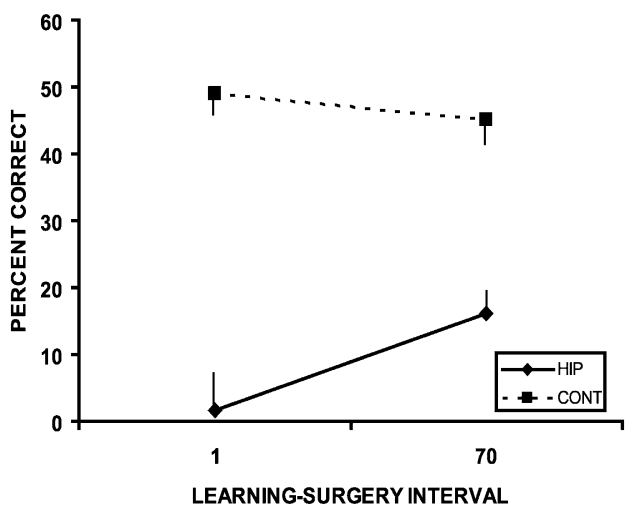

Figure 4. (A) Mean ( \pm SEM) percentage of correct responses during the third day of retraining in hippocampus-lesioned and control groups of experiments 1 and 2. (B) Mean ( \pm SEM) percentage of correct responses during the third day of retraining for each one of the four groups with extensive training used in experiments 1 and 2 (1-d control, 1-d hippocampal, 70-d control, and 70-d hippocampal). In this case, the performance for each group was calculated by subtracting the performance of each one of the four groups without prior experience from the performance of the corresponding groups with prior training (i.e., relearning percent correct - learning percent correct, on day 3 of retraining).

that the forgetting curves are completely different depending on the group. Specifically, while in control groups forgetting is observed and the performance deteriorates as the training-surgery interval increases (planned comparisons $F_{(1,32)}=4.20, P<0.05$ ), in the experimental groups the opposite tendency is observed, although no significant differences were found (planned comparisons $F_{(1,32)}=$ $1.24, P=0.27)$. Importantly, as a consequence of the foregoing, the difference between the performance of the 70-d hippocampal group and the 70-d control group on the third day of retraining was significantly smaller than that observed in the 1 -d groups (1-d groups $=49.4$ vs. $70 \mathrm{~d}$ groups $\left.=27.8, t_{(16)}=2.15, P<0.04\right)$.

In an effort to further analyze these data, for each one of the groups with previous experience employed in experiments 1 and 2 (1-d control, 1-d hippocampal, 70-d control, and 70-d hippocampal groups), a new performance percentage was calculated on day three of retraining. Specifically, the performance of each one of the groups without prior training was subtracted from the performance of the corresponding group with prior training (i.e., relearning percent correct minus learning percent correct, day three). So, the new score could, in the lesioned rats, compensate, at least partially, for a possible deficit in performance/navigation and highlight a possible temporal gradient. Figure $4 \mathrm{~B}$ depicts the performance of each of the four groups as calculated above. A two-way ANOVA (group $\times$ learning-surgery interval) showed only a significant effect of group $\left(F_{(1,32)}\right.$ group $=68.10, P<0.0001 ; F_{(1,32)}$ learning-surgery interval $=1.63, P=0.21 ; F_{(1,32)}$ interaction $=1.15$, $P=0.29)$. Since in the 1 -d hippocampus group the new score had produced a nonhomogeneous distribution (with positive and negative scores), we attempted to analyze with greater precision whether a temporal gradient for the two lesioned groups had appeared. In effect, a Kruskal-Wallis ANOVA revealed a significant effect between the 1- and 70-d hippocampal groups (performance: 1.6 vs. $16.1, H=3.64, P<0.05$ ). Thus, overall, given that at remote points certain preoperative information can still be expressed after a long period of retraining, these results suggest that the hippocampus might play a more decisive role for recent memory than it does for remote memory.

\section{Experiment 3: Neurotoxic lesions of the hippocampus after learning a nonallocentric task (a single extramaze cue)}

The third experiment was performed with the aim of investigating whether the animals in experiments 1 and 2 learned the spatial task using an allocentric strategy or, on the contrary, they used a guidance strategy. When a guidance strategy is used, rats learn to approach a prominent cue, which defines, by itself, the location of the goal. Unlike the two previous experiments, in this one, using the same four-arm plus-shaped maze, the goal arm was marked by a blinking light that in all trials maintained a constant radial and vertical distance with respect to the food cup in the goal arm. From trial to trial, the locations of the light and goal were changed randomly to a different arm. Also, the relation between the starting arm and the goal arm was controlled in such a way that at the end of the training (or the retraining) period the number of trials in which the goal arm was located to the right, left, or opposite the starting arm was similar. This created a situation in which the extramaze constellation of landmarks was not relevant, and it was necessary for the animal to use a guidance vs. an allocentric strategy to effectively resolve the spatial problem (O'Keefe and Nadel 1978). Presurgically, rats received eight trials per session and one session per day to reach a learning criterion (14 correct trials on two consecutive days). After a 1-2 d period, rats received bilateral NMDA $(n=7)$ or sham lesions $(n=7)$. Finally, $12 \mathrm{~d}$ after surgery the rats were retrained on the same spatial task until they reached criterion again.

Several studies have clearly suggested that the hippocampal memory system is necessary for the acquisition and retention of allocentric-allothetic tasks, but that hippocampal damage does not affect the acquisition of spatial problems based on a guidance strategy (Morris et al. 1982; McDonald and White 1993; Ramos 2000a; Save and Poucet 2000; but see Epp et al. 2008). Therefore, as the task used in experiment 3 is clearly solved by using a guidance strategy, we hypothesize that no retrograde amnesia would be observed after hippocampal lesions.

\section{Histology}

A schematic reconstruction of the hippocampal lesions appears in Figure 1. Two one-way ANOVAs indicated similar hippocampal damage between lesioned animals of this experiment and experiment $1(F<1)$ and experiment $2(F<1)$.

\section{Behavioral results}

Preoperative learning

As illustrated in Figure 5A, in the training phase (acquisition) the performance of both groups of animals was similar. A one-way 
A

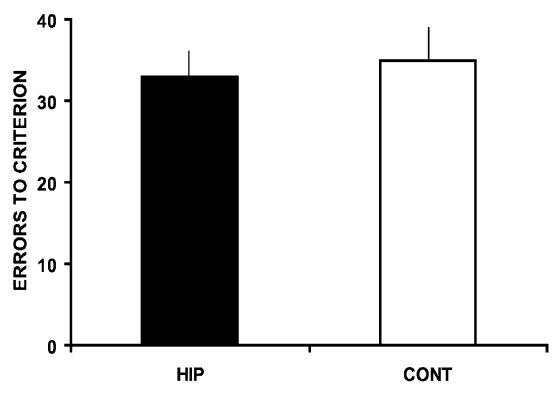

B

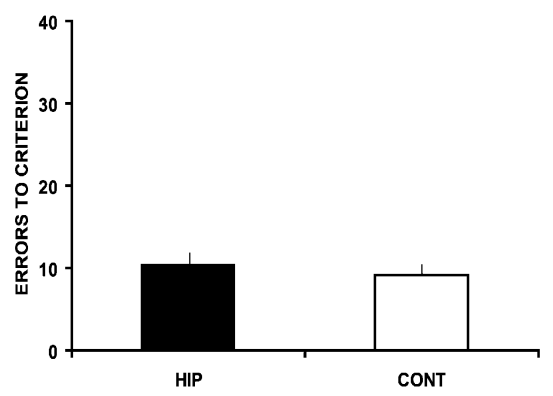

Figure 5. Mean ( \pm SEM) number of errors to criterion for the hippocampus-lesioned (HIP) and control (CONT) groups during the training (acquisition) $(A)$ and retraining $(B)$ phases of testing of experiment 3 .

ANOVA did not detect significant differences in relation to the number of errors to criterion $(F<1)$ or in the mean number of days required to reach criterion (hippocampus $=9.3 \mathrm{vs}$. control $=9.7$; $F<1$ ).

\section{Postoperative retention}

During the retraining phase (retention) the rats with damage to the dorsal hippocampus remembered the information learned during the acquisition phase as well as the control subjects. Thus, the performance of both groups did not differ significantly in the number of errors before reaching criterion $(F<1$; Fig. 5B) or in the number of days of retraining before reaching criterion (hippocampus $=4.5$ vs. control $=4.7 ; F<1$ ).

\section{Experiment 4: Neurotoxic lesions of the hippocampus} after learning a nonallocentric task (intramaze cue-based problem)

The aim of this experiment is similar to that indicated for experiment 3 . On this occasion, however, only a prominent intramaze cue oriented the animal toward the goal arm. Specifically, throughout the training and retraining periods, a piece of sandpaper was positioned along the entire floor of the goal arm. Otherwise, the behavioral procedure was identical to experiment 3.

\section{Histology}

As illustrated in Figure 1, the extent of the hippocampal lesions was very similar to that observed in previous experiments of this series. Two one-way ANOVAs found no significant differences between the extension of the damage observed in this experiment and that of experiment $1(F<1)$ and experiment $2(F<1)$.

\section{Behavioral results}

\section{Preoperative learning}

During the acquisition, one-way ANOVA did not detect significant differences in the number of errors to criterion $\left(F_{(1,12)}=1.63, P=\right.$ 0.22 ; Fig. $6 \mathrm{~A}$ ) or in the number of days to reach criterion (hippocampus $=6.5$ vs. control $=6.8 ; F_{(1,12)}=1.33, P=0.27$ ).

\section{Postoperative retention}

Data indicated an absence of retrograde amnesia after hippocampal lesions. During the retraining, the mean number of errors to criterion was similar in lesioned and sham-operated rats $\left(F_{(1,12)}=\right.$ $1.72, P=0.21$; Fig. $6 \mathrm{~B})$. Similarly, no significant differences were detected upon analyzing the mean number of days required to reach the relearning criterion (hippocampus $=3.3$ vs. control $=$ $2.8 ; F<1)$.

\section{Discussion}

In this series, we investigated the effect of the hippocampal lesions on the recall of a spatial task learned recently ( $1 \mathrm{~d}$ before the surgery) or remotely (70 d before the surgery). Several authors have suggested that for spatial memory, the hippocampus is continually necessary to update the position of the animal during its navigation to a goal (Knowlton and Fanselow 1998; Clark et al. 2007; Frankland et al. 2007). To counteract possible performance impairments caused by hippocampal lesions, in experiments 1 and 2 animals received early and extensive training in a spatial reference memory task in the radial maze. Moreover, during the postoperative phase of testing, they received 48 trials of retraining on three consecutive days in order to progressively facilitate the expression of spared memory. The main findings indicate that hippocampal damage produced retrograde amnesia for recent, as well as for remote, material. However, throughout the $3 \mathrm{~d}$ of postoperative

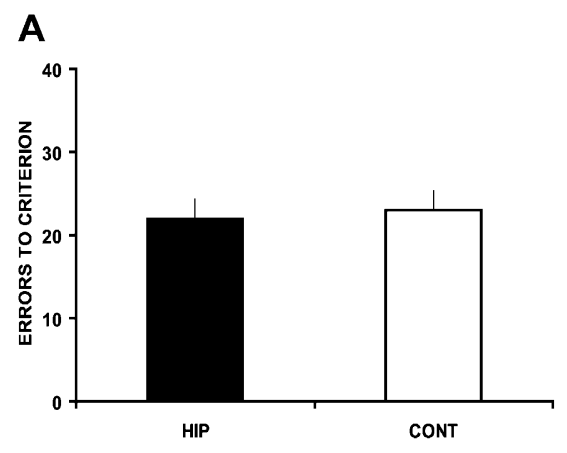

B

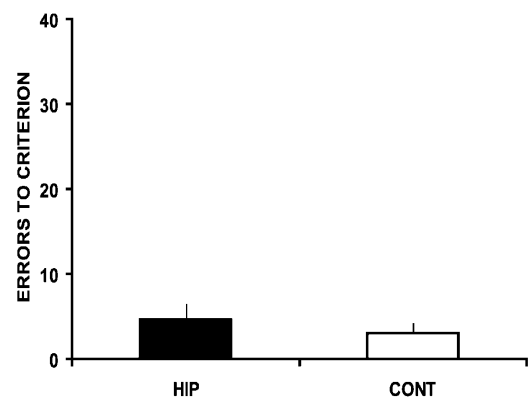

Figure 6. Mean ( \pm SEM) number of errors to criterion for the hippocampus-lesioned (HIP) and control (CONT) groups during the training (acquisition) $(A)$ and retraining $(B)$ phases of testing of experiment 4 . 
testing, the performance of the lesioned animals of the remote condition (experiment 2) showed significant improvement. In contrast, rats of the recent condition (experiment 1) did not improve significantly in the same period of time. As a result, the difference between the lesioned and control groups of the remote condition, on the third day of retraining, was significantly smaller than that observed in the groups of the recent condition. Importantly, a temporal gradient was detected between the 1-d lesioned group and the 70-d lesioned group when the performance obtained on the third day of retraining the groups without previous experience was subtracted from that of the corresponding groups that did have prior training.

The fact that the rats that learned the task remotely benefited more from the retraining suggests that certain spared spatial memory exists in these animals, and it may surface progressively as a result of a long period of retraining. This implies that the profound impairment observed in the 1-d lesioned rats cannot be attributed only to a performance deficit; a memory deterioration must exist in these animals. Moreover, the significant progression of performance observed in the 70-d lesioned rats cannot be explained by a reminder effect from the first day of retraining. If that were the correct explanation, the same improvement would have been observed in the 1-d lesioned group, and this is not the case. Also, the fact that the performance of the 70-d lesioned group with prior training was clearly superior to that of the additional lesioned group without previous experience, while such differences are not found in the 1-d lesioned groups, suggests that the improvement detected in the remote-lesioned rats is, in part, dependent on preoperative memory of the original place. The foregoing conclusions, however, should be considered to be tentative, mainly because of the large difference between the 70-d control and 70-d lesioned groups. The important finding here is, nonetheless, that despite these differences, other signs point toward more spared memory in the remote than in the recent lesioned group. In this regard, our results agree with previous studies that have found that the hippocampus is involved in memory for only a short time after learning. Thus, in the radial maze, studies using activity-dependent brain imaging techniques and reversible inactivation of the hippocampus have suggested that remote spatial memory becomes independent of the hippocampus as the consolidation process progresses (Bontempi et al. 1999; Maviel et al. 2004).

In contrast with the results of experiments 1 and 2, the data from experiments 3 and 4 indicate that, when the spatial task is learned exclusively on the basis of a guidance strategy, hippocampal damage did not produce retrograde amnesia. These data suggest that rats in experiments 1 and 2 must have acquired the spatial task by way of a strategy other than guidance, which probably requires the complex use of allocentric/allothetic cues to determine the correct direction to follow. If they had used a prominent cue for learning, i.e., a guidance strategy, lesioned rats in the first two experiments would not have manifested any deficit in the retraining phase, yet the retrograde amnesia observed in these animals was profound.

Some studies that have used lesion methods have suggested that the hippocampus is equally necessary for both recent and remote spatial memory (Laurent-Demir and Jaffard 1997; Winocur et al. 2005b; Haijima and Ichitani 2008). However, in none of the studies has there been a retraining period as long as the one applied here. One exception is the study of Kubie et al. (1999), in which the rats had to learn and remember a dry-land navigation task. After hippocampal damage, Kubie et al. (1999) observed spared remote spatial memory when the hippocampus was lesioned after a 14-wk training-surgery interval, but a profound retrograde amnesia was detected when the lesions took place $1 \mathrm{wk}$ after the end of training. Importantly, the spared-remote memory was only apparent after many reacquisition trials. Thus, in the early phases of retraining, hippocampus-lesioned animals of the remote group performed at chance. In this regard, the results of our present study are similar to the ones communicated by Kubie et al. (1999), which also suggest that an extensive and early training period is not able to overcome the initial postoperative deficit. The fact that the hippocampus-damaged rats in our study and in the one by Kubie et al. (1999) need a high number of reacquisition trials to express remote memory could reflect some performance impairment caused by hippocampal damage. In our study a relatively long period of retraining was able to partially compensate for the performance impairment, but in studies that have used short periods of postoperative testing it has been difficult to "catch" a memory effect (Haijima and Ichitani 2008).

In agreement with the aforementioned conclusions, several lines of evidence support the idea that the hippocampus is necessary on a continual basis for performance, as it updates the spatial position of the rat during the course of navigation. First, rats with fornix lesions seem unable to learn how to navigate to a hidden platform ("getting there") although they do appear to be able to learn where the platform is located ("knowing where") (Whishaw et al. 1995). Second, rats with hippocampal damage present a clear decline in path integration (or dead-reckoning). In this case the animal must continually compute its position in space in relation to a starting point by integrating the body movement cues generated during its navigation (Whishaw et al. 1997; Etienne and Jeffrey 2004). In fact, place cells, besides responding to incoming perceptual information, are activated by proprioceptive and vestibular signals generated by movement, suggesting that a crucial role is played by the hippocampus in integrating signals during navigation (Sharp et al. 1995). In addition, head direction cells have been identified in the hippocampus, and the firing properties of such cells are determined by body movements (Redish 2001). Third, electrophysiological data suggest that place cells can function as prospective memory neurons, becoming activated when the rat reaches the goal (Hok et al. 2007) or just before the animal makes a correct turn (Ferbinteanu and Shapiro 2003). Globally speaking, the data set forth above suggest that the hippocampus might form part of a circuit that is in charge of organizing accurate trajectories in space during the navigation. In order to attain optimal navigation, hippocampal cells would have to continually integrate both selfmotion (idiothetic) cues and distal visual (allothetic) cues in order for the animal to successfully reach the goal. From this point of view, therefore, it could be expected that the hippocampal lesions do not eliminate the spatial memory "per se," but rather they interfere with the expression of that spatial memory. Our data support this idea by showing the need for a long period of retraining in order for the 70-d hippocampus-damaged rats to be able to express spared memory in comparison with 1-d lesioned rats.

In addition to the magnitude of the retention/retraining period, an important difference among the various studies that have addressed the hippocampal function in remote spatial memory is the navigational demands of the spatial task employed. In general, the evidence indicates that the fewer navigational demands that a spatial memory task has, the more likelihood there is that a graded retrograde amnesia after hippocampal damage will be observed (Frankland et al. 2007). In this regard, some authors have suggested that the water maze task, in which very few studies have shown graded retrograde amnesia, has greater navigational demands than the radial-arm maze, in which a larger proportion of studies have observed spared-remote memory (Squire et al. 2004b; Frankland et al. 2007). Supporting this idea, reversible lesions of the hippocampus impair the expression of both recent and remote memory in the water maze in mice (Teixeira et al. 2006) and rats (Broadbent et al. 2006), but spared-remote memory 
is observed when a reference spatial memory task is employed in the radial maze (Maviel et al. 2004). Additionally, brain mapping studies show hippocampal activation during the expression of both recent and remote memory in the water maze (Teixeira et al. 2006; see also Gusev et al. 2005). In contrast, using a spatial reference memory task in the radial maze, no hippocampal activation at remote points is observed, but at recent points it is (Bontempi et al. 1999).

The pattern of results described above could probably explain why in a previous study performed in our laboratory, using the same task as in the present research, a temporally graded retrograde amnesia was obtained (Ramos 1998). In our previous study, the training and the retraining took place in a small, L-shaped experimental room in which the particular shape of the surroundings represented, in itself, an informative factor that guided the animal's search for the goal location (Ramos 2000b; see also Gibson et al. 2007 for a similar phenomenon). Importantly, the fact that two simultaneous series of cues (extramaze landmarks and the salient shape of the room) predicted the position of the goal arm made the spatial task a very easy one, with minimal navigational demands. Under these conditions it is easier to counteract a performance deficit during the course of the retention period, which could, in turn, facilitate the expression of spared preoperative memory. In support of this idea, two recent studies using new paradigms for the study of spatial memory that do not require substantial performance demands, the "village" task (Winocur et al. 2005a) and the paired-associative "event arena" (Tse et al. 2007), have shown a temporally graded retrograde amnesia following hippocampus damage. In consonance with the foregoing, Remondes and Schuman (2004) have shown in the Morris water maze that lesions of the temporoammonic projection from the entorhinal cortex to the CA1 region of the hippocampus produced retrograde amnesia of the task when the lesions were made $24 \mathrm{~h}$ following acquisition (recent memory), but spared memory was observed if the lesions were made $3 \mathrm{wk}$ after acquisition (remote memory). Importantly, in the study by Remondes and Schuman (2004), the temporoammonic damage did not affect new learning, suggesting that this lesion did not affect the normal functioning of the hippocampus, although it did disrupt the cortical-hippocampal interactions necessary for consolidation.

Last, the fact that most of the studies reviewed above have employed complete hippocampus lesions, while only dorsal lesions were made in our study, is worthy of certain discussion. First of all, using the Morris water maze and the Oasis maze, a dryland version of the water maze, Clark et al. (2005b) observed that dorsal hippocampal lesions, made after training, impaired the performance of both tasks to the same degree as complete lesions. These data agree with the initial studies by Moser et al. (1995), which found that small blocks of the hippocampus are sufficient for learning a reference memory task in a water maze, provided that the block is located within the dorsal hippocampus. The same group showed that dorsal hippocampal lesions impaired the acquisition of spatial learning in the water maze more than equally large ventral lesions (Moser et al. 1993; Moser and Moser 1998). Second, using a four-baited/four-unbaited version of the eight-arm radial-maze task, Pothuizen et al. (2004) showed that excitotoxic lesions of the dorsal hippocampus were as effective as complete lesions for disrupting both reference and working spatial memory; however, rats with ventral lesions performed the task almost as well as the controls did. Third, it has been suggested that the ventral hippocampus is necessary in various nonspatial learning and memory paradigms that involve, principally, stressand anxiety-related processes (Kjelstrup et al. 2002; Bannerman et al. 2004) or some aspect of temporal processing of long CS-US trace intervals in conditioning (Koh et al. 2009). Overall, therefore, the above papers suggest that complete lesions probably would have changed the final results of the present study very little. However, future investigations should look into whether the ventral hippocampus plays some role in the consolidation of spatial memory in our specific paradigm.

To conclude, using a highly demanding navigational task based exclusively on the extramaze landmarks of a regular-shaped room, hippocampal lesions produce a profound retrograde amnesia independent of the training-surgery interval. However, with retraining, certain spared remote, but not recent, spatial memory is observed. Thus, the long period of testing could be partially compensating for a navigational/performance deficit.

\section{Materials and Methods}

\section{Subjects}

The subjects were 96 male Wistar rats from the breeding colony of the University of Granada (260-330 g at the time of surgery). Rats were housed singly and maintained on a 12:12 h light/dark cycle. Behavioral testing was performed during the light phase of the cycle. All experimental procedures were performed in conformity with European (86/609/EEC) and Spanish (BOE 252, 2005) legislation and were approved by the Ethics Committee for Animal Research of the University of Granada (protocol number: 25-2005).

\section{Surgery}

Under the effects of sodium pentobarbital anesthesia $(50 \mathrm{mg} / \mathrm{kg}$ ip, Sigma Chemical), the rats were placed in a David Kopf stereotaxic apparatus with the incisor bar adjusted so that lambda and bregma were level. Rats were randomly assigned to either an experimental or a control group. The lesioned subjects received bilateral injections of NMDA (Sigma Chemical, PBS, pH 7.4, 0.07 M) through the insertion of a 30-gauge stainless-steel cannula in eight sites of the dorsal hippocampus in relation to the interaural zero point (Paxinos and Watson 1998): $\mathrm{AP}=+5.9, L= \pm 1.6, V=+6.5$; $\mathrm{AP}=$ $+4.8, L= \pm 2.5, V=+6.5 ; \mathrm{AP}=+3.8, L= \pm 3.2, V=+6.5$; and $\mathrm{AP}=$ $+3.0, L= \pm 4.0, V=+5.4$. The neurotoxin was administered in a $0.4-\mu \mathrm{L}$ volume at each site through the cannula that was attached to a $5-\mu \mathrm{L}$ Hamilton microsyringe. Delivery of the solution was carried out with a Harvard apparatus pump set (model 22) at an infusion rate of $10 \mu \mathrm{L} / \mathrm{h}$. The cannula was left in situ for an additional $5 \mathrm{~min}$ before being withdrawn. The rats in the control groups underwent the same surgical procedure, except that no solution was administered through the cannula. Finally, dorsal hippocampal lesions were made instead of complete hippocampal lesions, because several studies have shown that the dorsal hippocampus is more important for spatial memory than is the ventral hippocampus (Moser et al. 1993; Pothuizen et al. 2004).

\section{Apparatus}

A four-arm plus-shaped maze was used. Each arm of the maze measured $60 \mathrm{~cm}$ in length $\times 10 \mathrm{~cm}$ in width and was connected to an octagonal central platform $35 \mathrm{~cm}$ in diameter. The walls of the central platform were made of transparent Plexiglas and were $15 \mathrm{~cm}$ in height. The walls of each arm were made of wood and measured $5 \mathrm{~cm}$ in height. The maze was $60 \mathrm{~cm}$ from the floor and a 200-W light bulb was hanging from the ceiling, $1.2 \mathrm{~m}$ above the center of the platform.

\section{Behavioral procedure}

\section{Experiments 1 and 2}

Since at the beginning of experiments 1 and 2, the rats were just weaned and still growing, water instead of food pellets was used as the reward. During the preoperative training, the animals were placed on a water deprivation schedule. Every morning the animals had access to tap water in their cages for $15 \mathrm{~min}, 1 \mathrm{~h}$ after the end of the training session. In the afternoon, between 5:00 and 5:15 p.m., rats again had water available in their cages. 
The water deprivation program began on postnatal day 25 and training began on postnatal day 28. Starting on postnatal day 22, all rat pups were handled for 10 min daily until the day training started. During the training rats received eight trials per session and one session per day on five consecutive days each week. The acquisition period ended after $40 \mathrm{~d}$ of training, when the animals were $84 \mathrm{~d}$ old. The order in which the different arms were used as starting arms was randomized in each daily session. A small burette with a spout was placed at the end of each arm, at $5 \mathrm{~cm}$ from the arm's floor. Only the burette in the goal arm (west) had water in it. The rat was considered to have made a choice when, having entered an arm, it crossed the halfway point with its four limbs. After a choice was made, the guillotine doors were lowered and the animal was left in the chosen arm for 7-8 sec. The rat was then picked up and confined in a box for an intertrial interval of 30 sec. Between trials, the maze was rotated $90^{\circ}$ in a clockwise direction to prevent the rats from using olfactory signals to reach the goal arm. During the postoperative relearning, the behavioral procedure was identical to that of the preoperative phase.

\section{Experiments 3 and 4}

In these experiments rats learned a spatial problem using a guidance strategy. In experiment 3 the cue employed for learning was an intermittent light given by a $60-\mathrm{W}$ light bulb. Every second the light bulb gave a flash of light lasting $0.5 \mathrm{sec}$. The light bulb was located $10 \mathrm{~cm}$ above the food cup of the goal arm. It was at a radial distance of $10 \mathrm{~cm}$ from the food cup and was $70 \mathrm{~cm}$ from the entrance to the goal arm. In experiment 4 , however, an intramaze cue was employed. Specifically, a piece of sandpaper measuring $10 \times 60 \mathrm{~cm}$ (80-grit) was positioned on the floor of the goal arm. In both experiments, since adults rats were used in this case, food was used as the reward instead of water. Two $45-\mathrm{mg}$ food pellets (PJ Noyes) were placed in the food cup located at the end of the goal arm. During the training, from trial to trial the location of the goal arm and of prominent stimulus (extra- or intramaze) were changed randomly. Also, the relation between the starting arm and the goal arm was controlled in such a way that at the end of the training period (or the retraining) the number of trials in which the goal arm was located to the right, left, or opposite the starting arm was similar. This created a situation in which the extramaze constellation of landmarks was not relevant, and it was necessary for the animal to use guidance vs. allocentric strategy to effectively resolve the spatial problem (O'Keefe and Nadel 1978). During the pre- and postoperative phases, training ended when each rat reached a learning criterion of at least 14 correct trials on two consecutive days.

\section{Histology}

When the behavioral testing was completed, the rats were deeply anesthetized with sodium pentobarbital $(80 \mathrm{mg} / \mathrm{kg}$ ip) and perfused intercardially with $0.9 \%$ saline, followed by $10 \%$ formalin. After extraction from the skull, the brains were post-fixed in $10 \%$ formalin for several days and in $10 \%$ formalin-30\% sucrose until sectioning. Coronal sections $(50 \mu \mathrm{m})$ were cut on a cryostat $\left(-17^{\circ} \mathrm{C}\right)$ and stained with cresyl violet, a Nissl stain.

\section{Acknowledgments}

This research was supported by a grant from the Spanish Ministry of Education and Science (General Office for Research) and the European Regional Development Fund-ERDF-(SEJ2006-03012). I am grateful to Dr. Andrés Catena and to Dr. Joaquín M.M. Vaquero for their helpful comments on this work. I also thank Juan Carlos Rodríguez and Fernando Garzón for their valuable technical assistance.

\section{References}

Anagnostaras SG, Maren S, Fanselow MS. 1999. Temporally graded retrograde amnesia of contextual fear after hippocampal damage in rats: Within-subjects examination. J Neurosci 19: 1106-1114.
Bannerman DM, Rawlins JN, McHugh SB, Deacon RM, Yee BK, Zhang WN, Pothuizen HHJ, Feldon J. 2004. Regional dissociations within the hippocampus-memory and anxiety. Neurosci Biobehav Rev 28: 273283.

Bayley PJ, Hopkins RO, Squire LR. 2006. The fate of old memories after medial temporal lobe damage. J Neurosci 26: 13311-13317.

Bolhuis J, Stewart CA, Forrest EM. 1994. Retrograde amnesia and memory reactivation in rats with ibotenate lesions to the hippocampus or subiculum. QJ Exp Psychol 47: 129-150.

Bontempi B, Laurent-Demir C, Destrade C, Jaffard R. 1999. Time-dependent reorganization of brain circuitry underlying long-term memory storage. Nature 400: 671-675.

Bright P, Buckman J, Fradera A, Yoshimasu H, Colchester ACF, Kopelman MD. 2006. Retrograde amnesia in patients with hippocampal, medial temporal, temporal lobe, or frontal pathology. Learn Mem 13: 545557 .

Broadbent NJ, Squire LR, Clark RE. 2006. Reversible hippocampal lesions disrupt water maze performance during both recent and remote memory tests. Learn Mem 13: 187-191.

Cho YH, Kesner RP. 1996. Involvement of entorhinal cortex or parietal cortex in long-term spatial discrimination memory in rats: Retrograde amnesia. Behav Neurosci 110: 436-442.

Cho YH, Beracochea D, Jaffard R. 1993. Extended temporal gradient for the retrograde and anterograde amnesia produced by ibotenate entorhinal cortex lesions in mice. J Neurosci 13: 1759-1766.

Cipolotti L, Shallice T, Chan D, Fox N, Scahill R, Harrison G, Stevens J, Rudge P. 2001. Long-term retrograde amnesia: The crucial role of the hippocampus. Neuropsychologia 39: 151-172.

Clark RE, Broadbent NJ, Zola-Morgan S, Squire LR. 2002. Anterograde amnesia and temporally graded retrograde amnesia for a nonspatial memory task following lesions of hippocampus and subiculum. I Neurosci 22: 4663-4669.

Clark RE, Broadbent NJ, Squire LR. 2005a. Impaired remote spatial memory after hippocampal lesions despite extensive training beginning early in life. Hippocampus 15: 340-346.

Clark RE, Broadbent NJ, Squire LR. 2005b. Hippocampus and remote spatial memory in rats. Hippocampus 15: 260-272.

Clark RE, Broadbent NJ, Squire LR. 2007. The hippocampus and spatial memory: Findings with a novel modification of the water maze. J Neurosci 27: 6647-6654.

Corkin S. 2002. What's new with the amnesic patient H.M.? Nat Rev Neurosci 3: 153-160.

Epp J, Keith JR, Spanswick SC, Stone JC, Prusky GT, Sutherland RJ. 2008. Retrograde amnesia for visual memories after hippocampal damage in rats. Learn Mem 15: 214-221.

Etienne AS, Jeffrey KJ. 2004. Path integration in mammals. Hippocampus 14: 180-192.

Ferbinteanu J, Shapiro ML. 2003. Prospective and retrospective memory coding in the hippocampus. Neuron 40: 1227-1239.

Frankland PW, Bontempi B. 2005. The organization of recent and remote memories. Nat Rev Neurosci 6: 119-130.

Frankland PW, Bontempi B, Talton LE, Kaczmarek L, Silva AJ. 2004. The involvement of the anterior cingulate cortex in remote contextual fear memory. Science 304: 881-883.

Frankland PW, Teixeira CM, Wang S-H. 2007. Grading the gradient: Evidence for time-dependent memory reorganization in experimental animals. Dev Neurosci 1: 67-78.

Gibson BM, Wilks TJ, Kelly DM. 2007. Rats (Rattus norvegicus) encode the shape of an array of discrete objects. J Comp Psychol 121: 130-144.

Gilboa A, Winocur G, Rosenbaum RS, Poreh A, Gao F, Black SE, Westmacott T, Moscovitch M. 2006. Hippocampal contributions to recollection in retrograde and anterograde amnesia. Hippocampus 26: 966-980.

Gusev PA, Cui C, Alkon DL, Gubin AN. 2005. Topography of Arc/Arg3.1 mRNA expression in the dorsal and ventral hippocampus induced by recent and remote spatial memory recall: Dissociation of CA3 and CA1 activation. J Neurosci 25: 9384-9397.

Haijima A, Ichitani Y. 2008. Anterograde and retrograde amnesia of place discrimination in retrosplenial cortex and hippocampal lesioned rats. Learn Mem 15: 477-482.

Hok V, Lenck-Santini PP, Roux S, Save E, Muller RU, Poucet B. 2007. Goalrelated activity in hippocampal place cells. J Neurosci 27: 472-482.

Kim JJ, Fanselow MS. 1992. Modality-specific retrograde amnesia of fear. Science 256: 675-677.

Kim JJ, Clark RE, Thompson RF. 1995. Hippocampectomy impairs the memory of recently, but not remotely acquired trace eyeblink conditioned responses. Behav Neurosci 109: 195-203.

Kirwan CB, Bayley PJ, Galván VV, Squire LR. 2008. Detailed recollection of remote autobiographical memory after damage to the medial temporal lobe. Proc Natl Acad Sci 105: 2676-2680.

Kjelstrup KG, Tuvnes FA, Steffenach HA, Murison R, Moser EI, Moser MB. 2002. Reduced fear expression after lesions of the ventral hippocampus. Proc Natl Acad Sci 99: 10825-10830. 
Knowlton BJ, Fanselow MS. 1998. The hippocampus, consolidation and online memory. Curr Opin Neurobiol 8: 293-296.

Koh MT, Wheeler DS, Gallagher M. 2009. Hippocampal lesions interfere with long-trace taste aversion conditioning. Physiol Behav 98: 103-107.

Kubie JL, Sutherland RJ, Muller RU. 1999. Hippocampal lesions produce a temporally graded retrograde amnesia on a dry version of the Morris swimming task. Psychobiology 27: 313-330.

Laurent-Demir C, Jaffard R. 1997. Temporally extended retrograde amnesia for spatial information resulting from afterdischarges induced by electrical stimulation of the dorsal hippocampus in mice. Psychobiology 25: $133-140$.

Lehmann H, Lacanilao S, Sutherland RJ. 2007. Complete or partial hippocampal damage produces equivalent retrograde amnesia for remote contextual fear memories. Eur J Neurosci 25: 1278-1286.

Lopez J, Wolf M, Lecourtier L, Cosquer B, Bontempi B, Dalrymple-Alford J, Cassel J-C. 2009. The intralaminar thalamic nuclei contribute to remote spatial memory. J Neurosci 29: 3302-3306.

Manns JR, Hopkins RO, Reed JM, Kitchner EG, Squire LR. 2003. Recognition memory and the human hippocampus. Neuron 37: 1-20.

Martin SJ, de Hoz L, Morris RGM. 2005. Retrograde amnesia: Neither partial nor complete hippocampal lesions in rats result in preferential sparing of remote spatial memory, even after reminding. Neuropsychologia 43: 609-624.

Maviel T, Durkin TP, Menzaghi F, Bontempi B. 2004. Sites of neocortical reorganization critical for remote spatial memory. Science 305: 96-99.

McDonald RJ, White NM. 1993. A triple dissociation of memory systems: Hippocampus, amygdala, and dorsal striatum. Behav Neurosci 107: 3-22.

Milner B, Corkin S, Teuber HL. 1968. Further analysis of the hippocampal amnesic syndrome: 14-year follow-study of H.M. Neuropsychologia 6: 215-234.

Milner B, Squire LR, Kandel ER. 1998. Cognitive neuroscience and the study of memory. Neuron 20: 445-468.

Morris RGM, Garrud P, Rawlins JN, O'Keefe J. 1982. Place navigation impaired in rats with hippocampal lesions. Nature 297: 681-683.

Moscovitch M, Nadel L, Winocur G, Gilboa A, Rosenbaum RS. 2006. The cognitive neuroscience of remote episodic, semantic and spatial memory. Curr Opin Neurobiol 16: 179-190.

Moser MB, Moser EI. 1998. Functional differentiation in the hippocampus. Hippocampus 8: 608-619.

Moser E, Moser M-B, Andersen P. 1993. Spatial learning impairment parallels the magnitude of dorsal hippocampal lesions, but is hardly present following ventral lesions. I Neurosci 13: 3916-3925.

Moser MB, Moser EI, Forrest E, Anderson P, Morris RGM. 1995. Spatial learning with a minislab in the dorsal hippocampus. Proc Natl Acad Sci 92: 9697-9701.

Mumby DG, Astur RS, Wiesend MP, Sutherland RJ. 1999. Retrograde amnesia and selective damage to the hippocampal formation: Memory for places and object discrimination. Behav Brain Res 106: 97-107.

Nadel L, Winocur G, Ryan L. 2007. Systems consolidation and hippocampus: Two views. Dev Neurosci 1: 55-66.

Noulhiane M, Piolino P, Hasboun D, Clemenceau S, Baulac M, Samson S. 2007. Autobiographical memory after temporal lobe resection: Neuropsychological and MRI volumetric findings. Brain 130: 3184-3199.

O'Keefe J, Nadel L. 1978. The hippocampus as a cognitive map. Clarendon, Oxford, UK.

Paxinos G, Watson C. 1998. The rat brain in stereotaxic coordinates. Academic London, UK.

Pothuizen HH, Zhang WN, Jongen-Rêlo AL, Feldon J, Yee BK. 2004 Dissociation of function between the dorsal and the ventral hippocampus in spatial learning abilities of the rat: A within-subject, within-task comparison of reference and working spatial memory. Eur J Neurosci 19: 705-712.

Ramos JMJ. 1998. Retrograde amnesia for spatial information: A dissociation between intra- and extramaze cues following hippocampus lesions in rats. Eur J Neurosci 10: 3295-3301.

Ramos JMJ. 2000a. Long-term spatial memory in rats with hippocampal lesions. Eur I Neurosci 12: 3375-3384.

Ramos JMJ. 2000b. Influence of the shape of the experimental room on spatial learning in rats. Physiol Behav 70: 351-357.

Redish AD. 2001. The hippocampal debate: Are we asking the right question? Behav Brain Res 127: 81-98.
Remondes M, Schuman EM. 2004. Role for a cortical input to hippocampal area CA1 in the consolidation of a long-term memory. Nature 431: 699703.

Ross RS, Eichenbaum H. 2006. Dynamics of hippocampal and cortical activation during consolidation of a nonspatial memory. J Neurosci 26: 4852-4859.

Salat DH, van del Kouwe AJW, Tuch DS, Quinn BT, Fischl B, Dale AM, Corkin S. 2006. Neuroimaging HM: A 10-year follow up examination. Hippocampus 16: 936-945.

Save E, Poucet B. 2000. Involvement of the hippocampus and associative parietal cortex in the use of proximal and distal landmarks for navigation. Behav Brain Res 109: 195-206.

Sharp PE, Blair HT, Tzanetos DB. 1995. Influence of vestibular and visual motion information on the spatial firing patterns of hippocampal place cells. J Neurosci 15: 173-189.

Shimizu E, Tang Y-P, Rampon C, Tsien JZ. 2000. NMDA receptor-dependent synaptic reinforcement as a crucial process for memory consolidation. Science 290: $1170-1174$.

Squire LR. 2009. The legacy of patient H.M. for neuroscience. Neuron 67: 6-9.

Squire LR, Stark CEL, Clark RE. 2004a. The medial temporal lobe. Annu Rev Neurosci 27: 279-306.

Squire LR, Clark RE, Bayley PJ. 2004b. Medial temporal lobe function and memory. In The cognitive neurosciences III (ed. MS Gazzaniga), pp. 691 708. MIT Press, London, UK.

Steinvorth S, Levine B, Corkin S. 2005. Medial temporal lobe structures are needed to re-experience remote autobiographical memories: Evidence from H.M. and W.R. Neuropsychologia 43: 479-496.

Sutherland RJ, Weisend MP, Mumby D, Astur RS, Hanlon FM, Koerner A, Thomas MJ, Wu Y, Moses SN, Cole C, et al. 2001. Retrograde amnesia after hippocampal damage: Recent vs. remote memories in two tasks. Hippocampus 11: 27-42.

Sutherland RJ, O'Brien J, Lehmann H. 2008. Absence of systems consolidation of fear memories after dorsal, ventral, or complete hippocampal damage. Hippocampus 18: 710-718.

Takehara K, Kawahara S, Kirino Y. 2003. Time-dependent reorganization of the brain components underlying memory retention in trace eyeblink conditioning. J Neurosci 23: 9897-9905.

Teixeira CM, Pomedli SR, Maei HR, Kee N, Frankland PW. 2006. Involvement of the anterior cingulate cortex in the expression of remote spatial memory. J Neurosci 26: 7555-7564.

Tse D, Langston RF, Kakeyama M, Bethus I, Spooner PA, Wood ER, Witter MP, Morris RGM. 2007. Schemas and memory consolidation. Science 316: $76-82$.

Wang S-H, Teixeira CM, Wheeler AL, Frankland PW. 2009. The precision of remote context memories does not require the hippocampus. Nat Neurosci 12: 253-255.

Whishaw IQ, Cassel J-C, Jarrard LE. 1995. Rats with fimbria-fornix lesions display a place response in a swimming pool: A dissociation between getting there and knowing where. J Neurosci 15: 5779-5788.

Whishaw IQ, McKenna JE, Maaswinkel H. 1997. Hippocampal lesions and path integration. Curr Opin Neurobiol 7: 228-234.

Wiltgen BJ, Sanders MJ, Anagnostaras SG, Sage JR, Fanselow MS. 2006 Context fear learning in the absence of the hippocampus. J Neurosci 26: 5484-5491.

Winocur G. 1990. Anterograde and retrograde amnesia in rats with dorsal hippocampal or dorsomedial thalamic lesions. Behav Brain Res 38: 145154.

Winocur G, Moscovitch M, Fogel S, Rosenbaum RS, Sekeres M. 2005a. Preserved spatial memory after hippocampal lesions: Effects of extensive experience in a complex environment. Nat Neurosci 8: 273275.

Winocur G, Moscovitch M, Caruana DA, Binns MA. 2005b. Retrograde amnesia in rats with lesions to the hippocampus on a test of spatial memory. Neuropsychologia 43: 1580-1590.

Zola-Morgan SM, Squire LR. 1990. The primate hippocampal formation: Evidence for a time-limited role in memory storage. Science 250: 288290.

Received May 13, 2009; accepted in revised form July 14, 2009. 


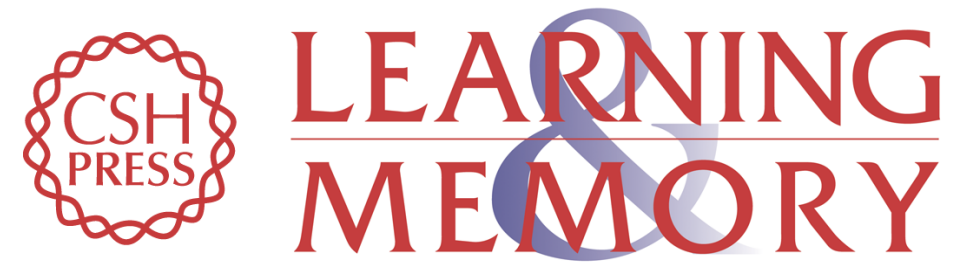

\section{Remote spatial memory and the hippocampus: Effect of early and extensive training in the radial maze}

Juan M.J. Ramos

Learn. Mem. 2009, 16:

Access the most recent version at doi:10.1101//m.1480309

References This article cites 77 articles, 28 of which can be accessed free at:

http://learnmem.cshlp.org/content/16/9/554.full.html\#ref-list-1

License

Email Alerting Receive free email alerts when new articles cite this article - sign up in the box at the Service top right corner of the article or click here. 